\title{
Arhailisest ja sekundaarsest kirjast ning kultuurimuutustest
}

\author{
$\underline{\text { Art Leete }}$
}

Järgnevas põgusas ülevaates eeldan, et maastiku tunnetamine ning orienteerumine (eriti traditsioonilised orienteerumisstrateegiad) on teatud mõttes seostatavad 'märgi', 'kirja' ja 'keele' mõistetega. See seos on loodav nimetatud mõistete äärmuslikult laia ning üldistava tõlgenduse puhul.

J. Derrida määratleb kirja arhikirjana, kõne ja kirja ühise juurena (Derrida 1995: 17). Kirjast lähtuvalt pannakse Derrida poolt kahtluse alla arhia, absoluutse alguse, algupära otsingud. Kiri ise aga ei algagi kuskil (samas: 23). Derrida sõnul viitab tähistamisest vaba "tähendusekogemus", puhas "tähenduskiht" teatavale keele-eelsele või märgisüsteemieelsele kihile (samas: 39-40). Kirja esialguseks loeb Derrida igasuguse erinevuse*1 (samas: 33) või erinevuste (samas: 35), erinevusjälgede ja ruumistamise süstemaatilise mängu (samas: 36) või ka erinevuse mängu (samas: 24), "gramm'i", "varu", "lahtilõike", "lünga", "lisandi", "äär-markeering-ääreala" (samas: 51), "jälje" (samas: 78) "mõra" (samas: 111), millele "...ei eelne kohaloleva võimalikkuse absoluutset ja jagamatut ühtsust..." (samas: 18). Erinevus on kohalolu edasilükkaja, "...see, millest lähtudes teda tema representandi, märgi või jäljena ihaldatakse või kuulutatakse..." (samas: 18). Erinevused pole fikseeritud suletud, staatilisse struktuuri, vaid on transformatsiooni tagajärg (samas: 36).

Puhas tähenduskiht viitab teatud keele-eelsele või märgisüsteemieelsele kihile, mida Husserl nimetab väljenduseelseks (samas: 40). Kiri või tekst ei taandu Derridal graafilisuse meelelisele või nähtavale kohalolule (samas: 77).

Kiri juurdub justkui mingis algses püsimatus mitteühesugususes. See juurdumine on küll ilmselt eelkõige olemuslik. Ent sellisena ka loogiliselt ajalises plaanis konstrueeritav. Seda enam, et on näiteks väidetud, et üldine semiootiline võime (s.t oskus kasutada mingeid esemeid või objekte peale nende otsese funktsiooni ka millegi tähistajatena) tekkis inimese eellastel vähemalt 13 miljonit aastat tagasi (Allik 1995: 33). Taoline oskus luua ja kasutada sümboleid kujunes kompleksses interaktsioonis koos muude inimest teistest elusolenditest eristavate tunnustega (Geertz 1973: 67-68).

Lähtudes eelnevalt kirjeldatud kirja-algupärast ning püüdes 'kirja' mõistet siduda kultuurimuutuste ning traditsiooniliste orienteerumisstrateegiate semiootilise algupäraga, defineerime nimetatud mõiste järgnevalt kahel erineval moel.

Primaarne ehk arhailine kiri on kultuurispetsiifiline kommunikatiivne manipuleerimine keskkonnaerinevustega. Selle rakendumine lähtub eeldatavast ruumi heterogeensuse, asümmeetria ja katkendlikkuse printsiibist. Ehk teisiti öelduna - see on traditsioonilise kommunikatsiooni üldstrateegia või vastav individuaalne käitumine loodusobjektide ja -nähtuste ebakorrapärasuste jälgimise ja/või nende tekitamise kaudu. Seega mõistame arhailise kirja puhul kirja äärmiselt laias mõttes.

Traditsioonilisi orienteerumisstrateegiaid võib samuti käsitleda kirja prototüüpidena. Maastik on vaadeldav ruumiliselt organiseerunud, potentsiaalse ning muutuva tähendustehulgana (vrd Farnell 1994: 931).

E. Sapir eristab ühiskonna primaarseid kommunikatiivseid protsesse, mis tulenevad avalikust käitumisest ja mida tinglikult võib nimetada "sotsiaalseks vihjeks". Nende hulka kuuluvad keel, 
zhestikuleerimine selle sõna kõige laiemas tähenduses, avaliku käitumise imiteerimine ning "suur ja halvasti määratletav implitsiitsete protsesside grupp" (Sapir 1993: 211). Antud juhul kuulub esmase kirja alla kogu "üldise kirjaoskuse" eelne/väline kommunikatsioon. R. A. Rappaport nimetab seda mittesümboolseks kommunikatsiooniks, mis on "...teatava sündmuse märgatav aspekt, mis viitab sama sündmuse teiste, märkamatute aspektide olemasolule" (Rappaport 1996: 381). Keskkonna objekt saab märgiks, kui teda tähenduslikult interpreteeritakse (vrd Voigt 1993: 64 (Peirce 1935)).

Sekundaarne kiri (seostub üldise kirjaoskusega) on kokkuleppeline, traditsiooniliselt ühtlustatud strateegia teabe säilitamiseks ja edastamiseks püsivalt visuaalselt tajutavas vormis. See on kirja sidumine keele teatud struktuuritasemega, teatud normatiivse sümboliseerituse astmega, mille kujunemist tõlgendatakse kirja tekkena. Sekundaarne kiri on kitsam, kanaliseeritum mõiste kui primaarne kiri. Tavalisemaks erinevuseks arhailise kirjaga loetakse selle, sümboolse (tihti alfabeetilise) kirja puhul Saussure'i poolt esimesena sõnastatud tähistaja suvalist seost tähistatavaga (Coulmas 1992: 253). Tihti tõlgendatakse seda kõrgkultuurilise päriskirjana, mille suhtes primaarne kiri toimib protokirjana.

Selget piiri päris kirja ja millegi olemuslikult eelneva või laiema vahele pole võimalik tõmmata. Üleminekud on segased ja raskesti fikseeritavad. Eristatakse kirjaoskusega ja kirjaoskuseta kultuure, samuti selliseid, kus kirjaoskus mingil astmel olemas on. Samuti eristatakse kultuure, kus kirjaoskus on üldine, ja selliseid, kus seda tunnevad vähesed (nn "spetsialistide kirjaoskus").

Kirja peetakse üheks olulisemaks tsivilisatsiooni tunnuseks. Sekundaarse kirja teke loetakse tihti identseks tsivilisatsiooni tekkega. M. McLuhan on näiteks arvanud, et tsivilisatsiooniks vajaliku ühetaolise aluse annab kultuurile alles foneetiline alfabeet (McLuhan 1964: 81). Kirjaoskus on kultuuri ühtlane nägemismeele avardamise töötlemine (samas: 84). Foneetilised alfabeedid ühtlustavad kultuure. Arhailised kirjad hoiavad kultuuri eripära (samas: 87).

Taoline lähenemisviis on kahtlemata mõnevõrra lihtsustav. Kontekstipärasemalt sõnastatuna oleks see aga ilmselt teatud määral vastuvõetav. Sest iga üksiku institutsiooni tekkimine või omandamine mõjutab kogu sotsiaalse süsteemi interaktsioonide kvaliteeti (Layton 1992: 86). Otsustava tähtsusega struktuurimuutus toimub aga juba "... küttimisega tegelevate ühiskondade teatud kategooriate sees" (Woodburn, cit. Gellner 1995: 436).

E. Gellneri järgi tuleneb "...kirjaoskusliku ühiskultuuri ("rahvuse") võim kaasaegse inimese üle ... vanade struktuuride hävitamisest; kunagi olid need struktuurid igale inimesele andnud identiteedi, ent nüüd on ta neis asjus sõltuv haridusest" (Gellner 1995: 206). "See kõik tähendab, et enamasti johtub pöördumine uude hariduse poolt edastatud etnilisusse nii tõmbest kui tõukest: uute töövõimaluste külgetõmme ühelt poolt ja teiselt poolt eemaletõukavus, mida tekitab hirm vanade turvalisust pakkunud sugulussuhete murenemise pärast (samas). Kultuurimuutuste protsessis võidakse aga jõuda ka olukorda, kus eksisteerivad kõrvuti sugukondlik lojaalsus struktuurile ja rahvuslik lojaalsus kirjaoskuslikule kultuurile (samas).

E. Gellner eristab metsikuid ja kultiveeritud kultuure, milledest viimaseid hoiab alal üldine kirjaoskus. Agraarajastu üks suuri innovatsioone ongi sekundaarne kirjaoskus, mis industriaalühiskonnas muutub üldiseks (Gellner 1995: 430). Kõrgkultuuride kirjakeeled ja suhtlemisstiilid muutuvad industriaalajastul "...palju mõjuvamalt autoriteetseteks ja normatiivseteks ning eelkõige muutuvad nad universaalseks ja üldlevinuks. Teisisõnu - tegelikult saab igaüks kirjaoskajaks ning suhtleb keerukas koodis, selgete "grammatiliste" (reeglipäraste) lausete ja mitte kontekstiga seotud mõmina ning noogutuste abil" (Gellner 1994: 2654). Taolise vahe sisseviimine on aga tegelikult pealiskaudne, kuna kasutatav keel on alati kontekstipärane (Linell 1992: 259). Sõnade ja märkide tähendused on potentsiaalsed ning võimaldavad teatud kindlaid interpretatsioone spetsiifilistes kontekstides (samas). 
Manipuleerimine keskkonnavariatsioonidega säilib arhailise kihistusena ka hilisemates heterogeensetes kommunikatsioonitehnikates. J. Lotmani ja teiste Tartu koolkonna semiootikute poolt on rõhutatud asjaolu, et üheski kultuuris ei ringle mitte ainult hiljuti loodud, vaid ka vanad, kultuuri varasematele arengustaadiumidele vastavad tekstid. Tekst võib oma eri osades toetuda erineva ajalise sügavusega mälule, on heterogeenselt sifreeritud (Lotman 1992: 143, 144; Tulviste 1976: 47). "Kultuuri muutumisel säilivad olemasolevad mõtlemistüübid sedavõrd, kuivõrd need ka muutunud oludes osutuvad funktsionaalselt vajalikeks" (Tulviste 1976: 51).

J. Lotman eristab kaht algset keelt, millel kultuur geneetiliselt põhineb. Need on inimestevahelise suhtlemise igapäevane keel ja ruumi varjatud struktuurne mudel (Lotman 1992: 142).

M. Foucault' järgi moodustasid loomulikud märgid renessansi-eelses Euroopa kultuuris kõigi teiste märkide aluse ja nad polnud midagi muud kui elemendid, mis olid eristatud asjadest ja konstitueeritud märkidena teadvuse poolt. Sellistena olid nad ette dikteeritud, jäigad, ebamugavad selles mõttes, et mõistus ei saanud neid endale allutada (Foucault 1994: 96).

Renessansiaegses Euroopa kultuuris tunnetati loodust nii märgi- kui sarnasustesüsteemina enesessesulgununa nagu kahestunud kosmost (samas: 68). Ruumi objektide sarnasus ja keel põimusid ühises ruumis, vihjasid, osutasid teineteisele (samas: 65,74$). \underline{* 2}$

Varasematest eristuvad aga kokkuleppe alusel kehtestatud uusaegsed*3 märgisüsteemid, kus märk tähistajana on tähistatava objektiga seotud suvalise reeglistatud kokkuleppe alusel ning mida on kerge meelde jätta ja mõista (samas: 96). "...Märgid olid esemete koostisosad, 17. sajandil muutuvad aga kujutlusmoodusteks" (samas: 159). Loomulike märkide keel "...eksisteeris alguses vabas, esialgses olekus, lihtsas materiaalses vormis, nagu kiri, nagu templimärk asjade peal... mingis mõttes on see keele kihistus ainus ja absoluutne" (samas: 78). Loomulikud märgid on sügava samasuse suhte kaudu seotud sellega, millele nad osutavad (samas: 70). Hobbes'i järgi on keel esialgselt märgete süsteem, mille indiviidid on välja valinud eelkõige iseenda jaoks (samas: 115). 16. sajandi reaalne keel polnud ühtlane ja ühetaoline hulk sõltumatuid märke, milles asjad tunnetuvad nagu peeglis, avaldades üksteise järel oma spetsiifilise tõe. "See on pigem läbipaistmatu, saladuslik mass, mis puutub kord siin, kord seal kokku maailma figuuridega ja põimub nendega läbi, mille tulemusel nad kõik koos moodustavad märkide võrgustiku, milles igaüks võib mängida ja tegelikult mängibki kõigi teiste suhtes sisu või märgi, saladuse või osutuse rolli" (samas: 71). See märkide võrgustik haarab maailma äärest ääreni (samas: 66).

Uusaegsele inimesele näis endiselt "...reaalne geograafiline ja maine ruum, milles me asume /---/ ühtede olendite läbipõimumisena teistega sellises korras, mis võrreldes grandioosse taksonoomiate*4 ruumiga pole midagi muud kui juhus, korralagedus ja rikutus" (samas: 178). Tänu rakendatavale korrapärasele teoreetilisele struktuurile osutub aga uusaegses tunnetuses "...see, mille ettekujutus annab ebaselges olekus ja üheaegsuse vormis, olema haaratav analüüsile ja annab sellesamaga võimaluse keele lineaarseks hargnemiseks" (samas: 166). 17. sajandist muutubki märkide dispositsioon lineaarseks, olles määratud tähistaja ja tähistatava suhtega (samas: 78). Samas võib kord olla "...üheaegselt möödapääsmatu ja loomulik (mõtlemise suhtes) ja vägivaldne (asjade suhtes), kuna üks ja sama asi võib vastavalt viisile, kuidas teda vaadeldakse, asuda korrapära ühele või teisele seisukohale" (samas: 89).

Arhailise kultuuri orienteerumisstrateegiate ebamugavus kättesaadavale struktuursusele pürgivas klassikalisele antropoloogilisele tunnetusele on mõneti sarnane ebamugavusega teisel viisil kauge 17. sajandi (uusaja) eelse Euroopa kirjaoskuse mõistmise modelleerimisel. Mõtlemistüüp, mille alusel eri aegadel või eri kultuurides kirja mõistetakse, on suures osas erinev, sest erinevad on ka spetsiifilised ülesanded (kui nad ei vasta tegevusele, mis on kõikides kultuurides ühesugune), mida metsakultuuri loogika ning Euroopa kultuuri mõtlemise abil lahendatakse (vrd Tulviste 1976: 47, 
51; 1986: 104). Teadmine pole kunagi absoluutne, vaid kultuuritugenev (Johansen 1995). Võõra maailmakirjelduse-spetsiifilise mõtlemisviisi oimamine on aga raske ning seda modelleeritakse aegajalt müstika, kaemuse, hämaruse ja kadumisena, millega võõras kultuur on tunnetuskäigus asendanud tuttava kultuuri ratsionaalsuse, valguse, kohahoidmise ja fikseeritud struktuurid. Ehk nagu kirjutab Heinz Werner: "Kui puudub teoreetiline teadmine, hõivab selle koha maagiline tegevus" (Werner 1948, cit. Fearing 1971: 66).

Ja sarnane on asi ka arhailiste orienteerumisstrateegiate antropoloogilise interpreteerimisega. Nii nagu lapse ja looma tarkus (Allik \& Luuk 1980: 99) sõltub metsa- ja tundrarahvaste orienteerumise ja muu arhailise kommunikatsiooni ratsionaalsuski eelkõige uurija tarkusest.

\section{Allikad ja kasutatud kirjandus}

Allik, Jüri 1995. Inimeseks saamine. Ajalaval. Tartu-Helsinki, lk 17-35.

Allik, J. \& Luuk, A. 1980. Nägemispsühholoogia. Tallinn.

Baiburin, A. K. 1989. Semiotitseskije aspektõ funktsionirovanija vestsei. Etnografitseskoje izutsenije znakovõhh sredstv i kulturõ. Leningrad, lk 63-88.

Coulmas F. 1992. Writing systems. International Encyclopedia of Linguistics. Vol. 4, New YorkOxford.

Derrida J. 1995. Positsioonid. Tallinn.

Farnell B. M. 1994. Ethnographics and the moving body. Man. Vol. 29, No. 4, pp. 929-974.

Fearing F. 1971. An Examination of the conception of Benjamin Whorf in the light of theories of perception and cognition. Language in Culture. Chicago, pp. 47-81.

Foucault, M. 1994 Slova i vestsi. Arheologija gumanitarnõhh nauk. Sankt-Peterburg.

Geertz C. 1973. The Interpretation of Cultures. USA.

Gellner E. 1994. Rahvused ja rahvuslus. Akadeemia, nr 10, lk 2207-2238; nr 11, lk 2429-2462; nr $12,1 \mathrm{k} 2653-2686$.

Gellner E. 1995. Rahvused ja rahvuslus. Akadeemia, nr 1, lk 197-222; nr 2, lk 419-446, nr 3, lk 643-663.

Johansen U. 1995. Kognitiivne etnoloogia. Loengukonspekt, käsikiri, Tartu.

Layton R. 1992. The Anthropology of Art. Cambridge.

Linell P. 1992. Written Language and Linguistic Theory. International Encyclopaedia of Linguistics. Oxford, pp 259-260.

Lotman, J. 1992. Tekst i poliglotizm kulturõ. Izbrannõje stati, t. 1. Tallinn, lk 142-147.

McLuhan M. 1964. Understanding Media. The Extensions of Man. New York-Toronto-London.

Rappaport R. A. 1996. Rituaal, pühadus ja küberneetika. Akadeemia, nr 1, lk 153-165; nr 2, lk 379391.

Sapir, E. 1993. Kommunikatsija. Izbrannõje trudõ po jazõkoznaniju i kulturologii. Moskva, lk 210215.

Tulviste, P. 1976. Mõtlemise muutumisest ajaloos. Tallinn.

Tulviste, P. 1986. Tipõ mõslenija i traditsionnõje zanjatija. Kultura narodnostei Severa: traditsii $i$ sovremennost. Novosibirsk, lk 100-108.

Voigt, V. 1993. Ikonitsnost rannihh form iskusstva. Ot mifa k literature. Moskva, lk 61-80. 


\section{Kommentaarid}

1 erinevus (differance) on nii eristamise kui edasilükkamise tähendusi hõlmav märksõna, mis "...võib Derrida jaoks neljal moel märkida liikumist, mis loob kohaloluefekti" (H. Krulli kommentaarist J. Derrida raamatu "Positsioonid" eestikeelsele tõlkele (1995: 125). Esiteks viitab erinevus liikumisele, "...mille sisuks on edasilükkamine" (Derrida 1995: 17). Teiseks loob erinevus erinemisi, on ühiseks juureks kõigile meie keele mõistete opositsioonidele (samas: 18). Kolmandaks on see kõigi tähenduste ja struktuuride tingimus (samas). Neljandaks on erinevus määratletav "...olemise ja oleva vahelise erinevusena" (samas: 20).

2 Etnoloogilist perspektiivi silmas pidades on samuti väidetud, et kõik esemed on sisuliselt märgid ja vastupidi (Baiburin 1989: 71).

3 M. Foucault peab "uusaja" all silmas perioodi 17.-18. sajandini. Sel ajal vahetus tunnetuses senine Galileist ja Descartes'ist alguse saanud looduse üleüldise ning ühese korrastatuse printsiip looduse katkendlikkuse nõudega (Foucault 1994: 177, 325).

4 M. Foucault' järgi on "taksonoomia" 17.-18. sajandi klassikalist epohhi iseloomustav vaimne nähtus, mis on koos selle jaoks konstrueeritud märgisüsteemiga vajalik keeruliste objektide (ettekujutuste ja kogemuses antu) korrastamiseks. Rakendatav analüüs peab näitama, millisel moel varjatud olemise pidevus võib ajalises seoses taastekkida katkendlikes ettekujutustes. Nende uuringute arengut raamisid korra kehtestamisena antud teadmiste nõudmised. Taksonoomia määrab olemuste üldise seaduse ja samal ajal nende tunnetamise tingimused (Foucault 1994: 106-108). 